\title{
Simultaneous administration of high-dose
}

\section{atorvastatin and clopidogrel does not interfere with platelet inhibition during percutaneous coronary intervention}

This article was published in the following Dove Press journal:

Clinical Pharmacology:Advances and Applications

3 June 2016

Number of times this article has been viewed

\author{
Rolf P Kreutz ${ }^{1,2}$ \\ Jeffrey A Breall' \\ Anjan Sinha' \\ Elisabeth von der Lohe' \\ Richard J Kovacs' \\ David A Flockhart ${ }^{2, \dagger}$ \\ 'Krannert Institute of Cardiology, \\ 2Division of Clinical Pharmacology, \\ Indiana University School of Medicine, \\ Indianapolis, IN, USA
}

tDavid A Flockhart passed away on November 26, 2015
Correspondence: Rolf P Kreutz Krannert Institute of Cardiology, Indiana University School of Medicine, I80 I North Senate Boulevard, MPC2, ME400, Indianapolis, IN 46202-1228, USA

Tel +l 3179620500

Email rkreutz@iu.edu
Background: Reloading with high-dose atorvastatin shortly before percutaneous coronary interventions (PCIs) has been proposed as a strategy to reduce periprocedural myonecrosis. There has been a concern that statins that are metabolized by cytochrome P450 3A4 may interfere with clopidogrel metabolism at high doses. The impact of simultaneous administration of high doses of atorvastatin and clopidogrel on the efficacy of platelet inhibition has not been established.

Methods: Subjects $(n=60)$ were randomized to receive atorvastatin $80 \mathrm{mg}$ together with clopidogrel $600 \mathrm{mg}$ loading dose $(\mathrm{n}=28)$ versus clopidogrel $600 \mathrm{mg}$ alone $(\mathrm{n}=32)$ at the time of PCI. Platelet aggregation was measured at baseline, 4 hours after clopidogrel loading dose, and 16-24 hours after clopidogrel loading dose by light transmittance aggregometry using adenosine diphosphate as agonist.

Results: Platelet aggregation was similar at baseline in both the atorvastatin and the control groups (adenosine diphosphate $10 \mu \mathrm{M}$ : $57 \% \pm 19 \%$ vs $61 \% \pm 21 \% ; P=0.52$ ). There was no significant difference in platelet aggregation between the atorvastatin and the control groups at 4 hours $(37 \% \pm 18 \%$ vs $39 \% \pm 21 \% ; P=0.72)$ and $16-24$ hours post-clopidogrel loading dose ( $35 \% \pm 17 \%$ vs $37 \% \pm 18 \% ; P=0.75$ ). No significant difference in incidence of periprocedural myonecrosis was observed between the atorvastatin and control groups (odds ratio: 1.02; 95\% confidence interval 0.37-2.8).

Conclusion: High-dose atorvastatin given simultaneously with clopidogrel loading dose at the time of PCI does not significantly alter platelet inhibition by clopidogrel. Statin reloading with high doses of atorvastatin at the time of PCI appears to be safe without adverse effects on platelet inhibition by clopidogrel (ClinicalTrials.gov: NCT00979940).

Keywords: clopidogrel, atorvastatin, myocardial infarction, percutaneous coronary intervention, platelet aggregation

\section{Introduction}

High-dose statin therapy has been well established in the medical therapy of acute coronary syndromes (ACS) and in secondary prevention of cardiovascular disease. Beyond the low-density lipoprotein lowering and high-density lipoprotein raising properties, pleiotropic off-target effects of statins have been invoked in the dramatic reduction of thrombotic cardiovascular events. In the PROVE-IT TIMI 22 trial, intensive therapy with atorvastatin $80 \mathrm{mg}$ daily was superior to pravastatin $40 \mathrm{mg}$ daily in reducing ischemic events after ACS with a $16 \%$ relative risk reduction for a composite end point of death, myocardial infarction, documented unstable angina requiring hospitalization, revascularization, 
and stroke in the atorvastatin group. ${ }^{1}$ Similarly, others have investigated the beneficial properties of pretreatment with statins prior to elective percutaneous revascularization. A meta-analysis including nine trials documented an odds ratio of 0.45 for the occurrence of periprocedural myonecrosis in patients treated with statins prior to coronary intervention. ${ }^{2}$ Whereas earlier studies included patients who were pretreated with statins for at least 2 days prior to percutaneous coronary intervention (PCI), more recent trials have suggested that shorter pretreatment with statins may provide similar protection. ${ }^{3,4}$ In the NAPLES II study, atorvastatin $80 \mathrm{mg}$ administered 24 hours prior to PCI significantly reduced the incidence of myocardial infarction in statin-naïve patients. ${ }^{4}$ Similarly, in the ARMYDA-RECAPTURE study, reloading with atorvastatin $80 \mathrm{mg} 12$ hours prior to PCI and $40 \mathrm{mg}$ immediately pre-PCI in patients on chronic statin therapy reduced the 30-day major adverse cardiovascular event rate from $9.4 \%$ to $3.7 \%$ ( $P=0.037)$. ${ }^{5}$

Clopidogrel is a prodrug that requires metabolism by the hepatic cytochrome P450 (CYP) system (2C19, 1A2, 2B6, $3 \mathrm{~A} 4,3 \mathrm{~A} 5$, and $2 \mathrm{C} 9$ isoforms) to provide an active metabolite. ${ }^{6}$ It has been shown that inhibition of CYP metabolic capacity such as in the case of CYP2C19 by omeprazole and other proton pump inhibitors can lead to inadequate clopidogrel metabolite formation and reduced platelet inhibition. High residual platelet reactivity during treatment with clopidogrel is associated with significantly increased risk for adverse ischemic events after PCI. ${ }^{7}$

Due to the common CYP3A4 pathway shared by many of the statins (simvastatin, atorvastatin, lovastatin) and clopidogrel, there has been a concern for clinically significant interactions. A documented interaction between atorvastatin and clopidogrel was first described in 2003 by Lau et al, ${ }^{8}$ but other studies have not been able to confirm this effect using other platelet-testing modalities during maintenance therapy. ${ }^{9,10}$ Analysis of data from the CHARISMA trial studying 10,078 patients with statin therapy at baseline randomized to dual therapy with clopidogrel and aspirin versus aspirin alone did not demonstrate an effect of CYP3A4-metabolized versus non-CYP3A4-metabolized statins on clinical end points. ${ }^{11}$ In clinical practice, administration of maintenance statin and antiplatelet agents is often separate, with the former generally being prescribed in the evening and the latter in the morning. However, as early upstream administration of high-dose atorvastatin is being increasingly adopted for patients admitted with ACS, concomitant administration with clopidogrel is more likely to occur. No study has so far investigated the effects of simultaneous administration of high-dose atorvastatin
(80 mg) with high loading dose clopidogrel $(600 \mathrm{mg})$ on early platelet inhibition post-PCI.

\section{Methods}

\section{Study design and patient population}

The ESTATE study (effects of short term, high-dose aorvastatin therapy on periprocedural myonecrosis and platelet inhibition after PCI) is a randomized open-label pilot study to evaluate the effects of high-dose atorvastatin loading immediately before $\mathrm{PCI}$ on periprocedural myonecrosis and platelet inhibition. The study was approved by the Indiana University institutional review board. Written informed consent was obtained from all subjects. Subjects were eligible to be enrolled in the study if they were found to have significant coronary artery disease (CAD) with angiographic stenosis of $\geq 70 \%$ in one or more coronary arteries and were undergoing PCI for stable CAD. Patients undergoing catheterization for ST-elevation myocardial infarction (MI), non-ST elevation MI, or high-risk unstable angina were not enrolled in the study. Exclusion criteria included age $>85$ years and $<21$ years, recent myocardial infarction within the last month, cancer, renal failure with creatinine $>3.0 \mathrm{mg} /$ $\mathrm{dL}$, liver cirrhosis, lymphoproliferative disorder, pregnancy, thrombocytopenia $<150,000 / \mathrm{mm}^{3}$, coagulopathy (international normalized ratio [INR] $>1.5$ ), abnormal liver function tests, illicit drug use, history of statin intolerance, history of rhabdomyolysis, and planned use of glycoprotein IIb/IIIa inhibitors during PCI. Given that only very few patients who were referred for cardiac catheterization were statin naïve, we allowed subjects who had received simvastatin (which was the primary statin prescribed in our institution) to be enrolled if last simvastatin dose was administered at least 1 day prior. Subjects treated with atorvastatin, pravastatin, lovastatin, fluvastatin, or rosuvastatin were excluded from participation. All patients received aspirin $81-325 \mathrm{mg}$ orally prior to diagnostic catheterization.

Patients were randomized 1:1 to receive either atorvastatin $80 \mathrm{mg}$ orally or no additional atorvastatin, along with standard clopidogrel $600 \mathrm{mg}$ loading dose immediately prior to beginning of ad hoc PCI in the catheterization laboratory. Randomization occurred by opening of previously prepared sealed envelopes containing random allocation. The original sample size of the study $(\mathrm{n}=88)$ was calculated based on power 0.8 (two-sided alpha of 0.05 ) to detect the relative reduction in risk of periprocedural myonecrosis previously demonstrated in a study of moderate-dose atorvastatin pretreatment for several days before $\mathrm{PCI} .{ }^{3}$ The study was stopped after 60 subjects due to slower than expected enrollment. 


\section{Blood samples}

Blood samples were taken from arterial sheaths in the catheterization laboratory before administration of clopidogrel and atorvastatin. Follow-up blood samples were obtained by venipuncture 4 hours and 16-24 hours after loading dose of clopidogrel. All blood samples were directly transferred into vacutainer tubes containing $\mathrm{Na}$ citrate $3.2 \%$ and analyzed within 2 hours. Light transmittance aggregometry was performed with a Chronolog 700 aggregometer in platelet-rich plasma using platelet poor plasma as reference as previously described. ${ }^{12,13}$ Adenosine diphosphate (ADP) at $5 \mu \mathrm{M}, 10 \mu \mathrm{M}$, and $20 \mu \mathrm{M}$ was used as agonist. Platelet inhibition was defined as \% change in platelet aggregation from baseline in subjects not on baseline clopidogrel. Cardiac troponin I and creatinine kinase-MB (CK-MB) were measured 8 hours and 16 hours after PCI.

\section{End points}

Periprocedural myonecrosis was defined as a rise in cardiac troponin I above the upper limit of normal (ULN) for the assay at any time point after PCI. Periprocedural myocardial infarction was defined as postprocedural rise in CK-MB $>3 \times \mathrm{ULN}^{14}$

\section{Statistics}

Statistical analysis was performed using SPSS 22.0 (IBM Corporation, Armonk, NY, USA). Statistical significance was defined as $P<0.05$. Two-sided tests were conducted, and the values are represented as mean \pm standard deviation except as otherwise stated. Categorical variables were compared using the $\chi^{2}$-test. Normal distribution of continuous data was assessed by the Kolmogorov-Smirnov test. Unpaired twosided Student's $t$-test was used to compare normally distributed continuous data between the two groups. Multivariable linear regression analysis was performed using on-treatment platelet aggregation as dependent variable to evaluate the effects of assigned treatment arm with forward stepwise adjustment for baseline clinical variables, as well as adjustment for prior treatment with simvastatin and clopidogrel.

\section{Results}

Sixty patients who were undergoing elective PCI were randomized to receive either atorvastatin $80 \mathrm{mg}$ together with clopidogrel $600 \mathrm{mg}$ loading dose $(\mathrm{n}=28)$ or clopidogrel $600 \mathrm{mg}$ alone $(\mathrm{n}=32)$.

Table I Baseline demographics and clinical variables

\begin{tabular}{|c|c|c|c|}
\hline Variables & Atorvastatin $(n=28)$ & Control $(n=32)$ & $P$-value \\
\hline Age (years) & $62.6 \pm 10$ & $61.4 \pm 8$ & 0.6 \\
\hline Weight (kg) & $97.9 \pm 32$ & $103.7 \pm 48$ & 0.58 \\
\hline Male sex (\%) & $22 / 28(79 \%)$ & $25 / 32(78 \%)$ & 0.97 \\
\hline Race & & & 0.33 \\
\hline Caucasian (\%) & $22 / 28(79 \%)$ & 29/32 (9/\%) & \\
\hline African American (\%) & $5 / 28(18 \%)$ & $3 / 32(9.4 \%)$ & \\
\hline Asian (\%) & $\mathrm{I} / 28(4 \%)$ & $0 / 32(0 \%)$ & \\
\hline Prior CAD (\%) & $17 / 28(61 \%)$ & $22 / 32(69 \%)$ & 0.52 \\
\hline Congestive heart failure (\%) & $4 / 28(14 \%)$ & $5 / 32(16 \%)$ & 0.89 \\
\hline Diabetes mellitus (\%) & I3/28 (46\%) & $14 / 32(44 \%)$ & 0.84 \\
\hline Hypertension (\%) & $27 / 28(96 \%)$ & $30 / 31$ (97\%) & 0.92 \\
\hline Hyperlipidemia (\%) & $25 / 28(89 \%)$ & 29/32 (9/\%) & 0.86 \\
\hline Current smoking (\%) & I I/28 (39\%) & I0/32 (31\%) & 0.66 \\
\hline Baseline clopidogrel use (\%) & $7 / 28(25 \%)$ & 6/32 (19\%) & 0.56 \\
\hline Daily aspirin dose & & & 0.6 \\
\hline $81 \mathrm{mg}$ & II/28 (39\%) & $12 / 32(38 \%)$ & \\
\hline $162 \mathrm{mg}$ & $0 / 28(0 \%)$ & $\mathrm{I} / 32(3 \%)$ & \\
\hline $325 \mathrm{mg}$ & $17 / 28(61 \%)$ & $9 / 32(59 \%)$ & \\
\hline Prior treatment with simvastatin (\%) & $2 \mathrm{I} / 28(75 \%)$ & $22 / 32(69 \%)$ & 0.59 \\
\hline Proton pump inhibitor (\%) & $10 / 28(36 \%)$ & $13 / 32(4 \mid \%)$ & 0.63 \\
\hline ACE inhibitors (\%) & $17 / 28(61 \%)$ & $20 / 32(63 \%)$ & 0.76 \\
\hline Beta blockers (\%) & $26 / 28(93 \%)$ & $26 / 32(81 \%)$ & 0.29 \\
\hline Calcium channel blockers (\%) & $6 / 28(21 \%)$ & $5 / 32(16 \%)$ & 0.6 \\
\hline \multicolumn{4}{|l|}{ Coronary artery intervention } \\
\hline Left anterior descending artery & $9 / 28(32 \%)$ & I I/32 (34\%) & 0.86 \\
\hline Circumflex artery & $8 / 28(29 \%)$ & II/32 (34\%) & 0.63 \\
\hline Right coronary artery & $14 / 28(50 \%)$ & |3/32 (41\%) & 0.47 \\
\hline Number of stents implanted & $1.48 \pm 1.2$ & $1.58 \pm 0.8$ & 0.71 \\
\hline
\end{tabular}

Notes: Data presented as mean \pm standard deviation unless otherwise stated. Comparison of variables with Student's $t$-test for continuous variables and $\chi^{2}$ for categorical variables.

Abbreviations: CAD, coronary artery disease; ACE, angiotensin-converting enzyme. 
A

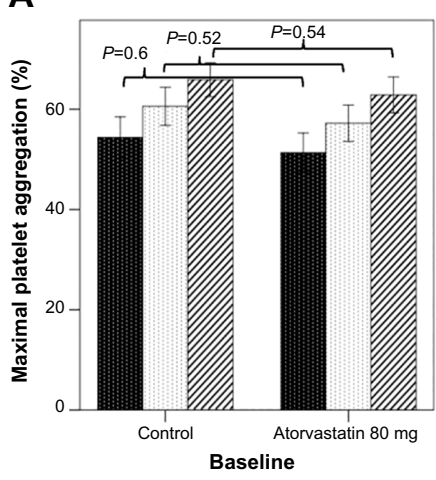

B

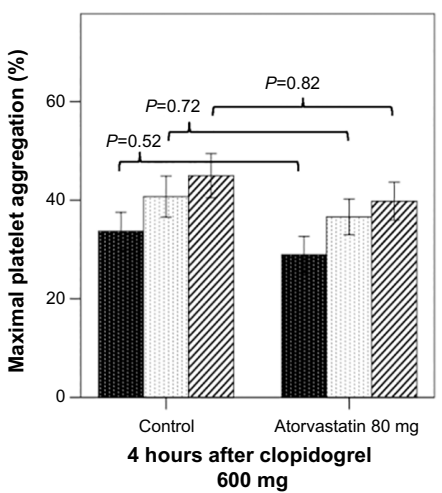

C

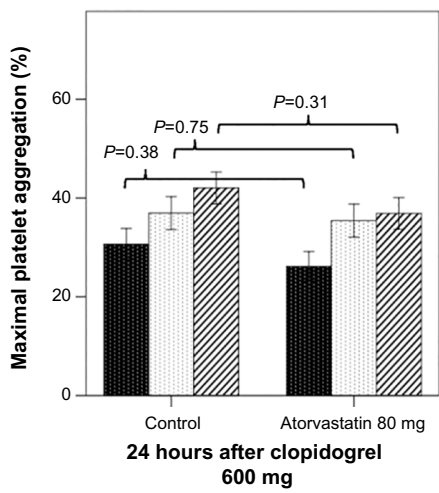

罪 $\mathrm{ADP} 5 \mu \mathrm{M}$ ADP $10 \mu \mathrm{M}$ T ADP $20 \mu \mathrm{M}$

Figure I Platelet aggregation.

Note: Maximal platelet aggregation measured at baseline (A), 4 hours (B), and 24 hours (C) after clopidogrel loading dose administration. Abbreviation: ADP, adenosine diphosphate.

One patient in the control (no atorvastatin) group received abciximab during the procedure at the discretion of the operator and was excluded from the analysis in the platelet substudy. Clinical variables of the subjects enrolled in the study are delineated in Table 1. There were no significant differences in the prevalence of clinical variables among groups. An average of 1.53 stents were implanted during the PCI, with $91 \%$ being drug-eluting stents. The target vessel was the left anterior descending artery in 33\%, the circumflex artery in $32 \%$, and the right coronary artery in $45 \%$ of cases.

At baseline prior to clopidogrel and atorvastatin administration, there was no significant difference in baseline platelet aggregation induced by ADP (Figure 1A). Platelet aggregation decreased at 4 hours after clopidogrel administration in both the atorvastatin and the control groups, with only minimal additional decrease in maximal platelet aggregation for all agonists studied at 16-24 hours (Figures 1B and C). There was a nonsignificant trend toward lower on-treatment maximal platelet aggregation in the atorvastatin group as compared to the control group at both time points. Similarly, there was no significant difference in platelet inhibition between the atorvastatin and control groups (Figures 2A and B). Multivariable linear regression analysis demonstrated no significant association between atorvastatin treatment arm and final on-treatment platelet aggregation after adjustment for clinical variables and pretreatment with clopidogrel or simvastatin (Table 2).

As previously reported by other investigators, a large number of subjects with uncomplicated PCI demonstrated periprocedural myonecrosis, as defined by elevation in cardiac troponin I above the ULN (Figure 2C). A smaller fraction of subjects demonstrated a rise in CK-MB above the ULN (Figure 2C). For both measures, no difference in incidence of periprocedural myonecrosis was observed between atorvastatin and control groups (troponin $>1 \times \mathrm{ULN}$ : odds ratio: $1.02 ; 95 \%$ confidence interval $[\mathrm{CI}] 0.37-2.8 ; P=0.97$; CK-MB > $1 \times$ ULN: odds ratio: $0.84 ; 95 \%$ CI $0.17-4.1$; $P=0.83)$. Two subjects in the atorvastatin group and one subject in the control group had a periprocedural myocardial infarction as defined by CK-MB rise above $3 \times$ ULN (odds ratio: 2.4 ; $95 \% \mathrm{CI} 0.2-28 ; P=0.5$ ).

\section{Discussion}

The results of our study suggest that simultaneous administration of high-dose atorvastatin $80 \mathrm{mg}$ and clopidogrel $600 \mathrm{mg}$ loading doses does not significantly increase the risk
A

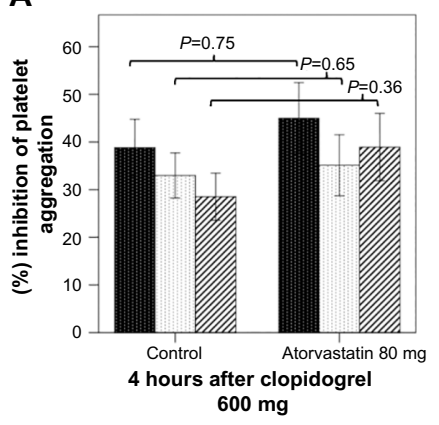

B

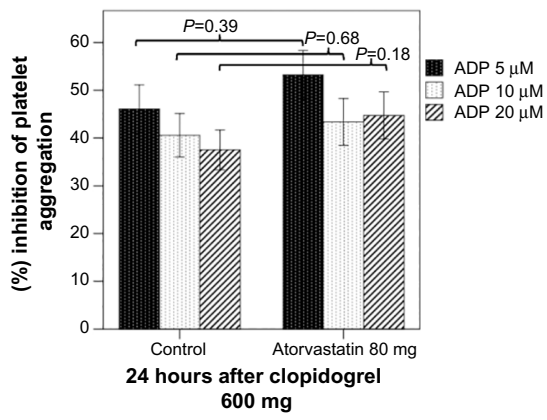

C

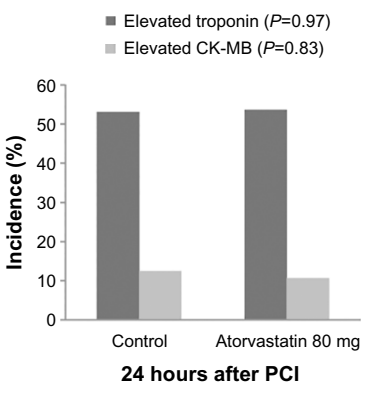

Figure 2 Platelet inhibition 4 hours (A) and 24 hours (B) after clopidogrel loading dose. Periprocedural myonecrosis after PCl (C). Abbreviations: ADP, adenosine diphosphate; CK-MB, creatinine kinase-MB; PCl, percutaneous coronary intervention. 
Table 2 Multivariable analysis of atorvastatin treatment with forward stepwise adjustment for baseline clinical variables and baseline clopidogrel and simvastatin treatment

\begin{tabular}{llll}
\hline $\begin{array}{l}\text { Dependent variable: } \\
\text { maximal platelet } \\
\text { aggregation at 16-24 hours }\end{array}$ & B-value & $\begin{array}{l}\text { 95\% Confidence } \\
\text { interval }\end{array}$ & P-value \\
\hline ADP 5 $\mu \mathrm{M}$ & -2.6 & -11.2 to 5.9 & 0.54 \\
ADP I0 $\mu \mathrm{M}$ & -0.7 & -10.7 to 9.3 & 0.89 \\
ADP $20 \mu \mathrm{M}$ & -4.0 & -13 to 5.1 & 0.39 \\
\hline
\end{tabular}

Abbreviation: ADP, adenosine diphosphate.

of high posttreatment platelet reactivity. While our study was not powered to demonstrate effectiveness in reducing the risk of periprocedural myocardial necrosis, given early termination of the study prior to targeted enrollment, and its pilot design, there was no difference in rates of periprocedural myonecrosis between subjects with and without concomitant high-dose atorvastatin administration. Previous studies by other investigators have suggested that high-dose atorvastatin given within a short time interval of 12 hours before PCI in patients with ACS may significantly reduce the risk of major cardiac events. In addition, updated guidelines recommend atorvastatin $40-80 \mathrm{mg} / \mathrm{d}$ or rosuvastatin $20-40 \mathrm{mg} / \mathrm{d}$ for secondary prevention of CAD. ${ }^{15}$ Thus, high doses of atorvastatin are increasingly being coprescribed in patients undergoing ad hoc PCI who may be started on clopidogrel concomitantly during an admission for an ACS. Many studies have evaluated the pharmacodynamic interactions of CYP3A4-metabolized statins and clopidogrel, with the majority evaluating the effects of chronic statin exposure on platelet reactivity. ${ }^{8-11,16-22}$ The timing of peak hepatic plasma exposure to the parent drugs may affect the extent of the pharmacodynamic interaction. The majority of studies examining statin-clopidogrel interaction have used traditional timing of dose administration, with statins being prescribed in the evening and antiplatelet agents in the morning. This may significantly influence the degree of interaction given that atorvastatin has a terminal half-life of $\sim 10$ hours. ${ }^{23}$ The majority of studies have demonstrated no consistent effect of atorvastatin treatment on clopidogrel response or clinical event rates, with few exceptions. Leoncini et $\mathrm{al}^{24}$ demonstrated improved platelet inhibition among patients randomized to high-dose atorvastatin who were previously found to have high platelet reactivity on clopidogrel. Some studies have suggested a modest pleiotropic anti-aggregatory effect of low-dose atorvastatin with reduction of ADP platelet reactivity after treatment for several months as well as improvement in prevalence of aspirin resistance, which could in part counterbalance a reduction in clopidogrel platelet inhibition. ${ }^{25,26}$ In contrast,
Park et $\mathrm{al}^{18}$ showed that changing atorvastatin to a non-3A4-metabolized statin significantly improved platelet inhibition among nonresponders to clopidogrel with high posttreatment platelet reactivity. Pelliccia et $\mathrm{al}^{27}$ recently reported that treatment with low-dose atorvastatin was associated with a small but significant increase in platelet reactivity among patients treated with clopidogrel, but this effect was only observed in subjects with high baseline on-treatment platelet reactivity by Verify Now assay. These conflicting results suggest that among certain individuals, in particular subjects who have high residual platelet reactivity during treatment with clopidogrel, concomitant treatment with high-dose atorvastatin could contribute to differences in pharmacodynamic response to clopidogrel. However, the results of this study suggest that simultaneous administration of high-dose atorvastatin and clopidogrel loading dose does not significantly impair early platelet inhibition after PCI, which is supported by lack of differences in outcomes among patients with statins in large clinical trials of clopidogrel. ${ }^{11,28,29}$

Limitations of this study include the open-label study design and that not all patients were naïve to statins and clopidogrel at the time of enrollment. Also, no other platelet agonists were studied other than ADP. Additional limitations are the relatively small sample size and the premature termination of the study after slow enrollment, leading to decrease in power to detect significant differences in incidence of periprocedural myonecrosis.

\section{Conclusion}

The results of our study indicate that simultaneous administration of high-dose atorvastatin and clopidogrel prior to PCI appears to be safe and does not significantly alter platelet inhibition by clopidogrel.

\section{Acknowledgments}

This study was supported in part by the Indiana Clinical and Translational Sciences Institute funded in part by Grant Number (RR025761) from the National Institutes of Health, National Center for Research Resources, Clinical and Translational Sciences Award, as well as the Indiana University Health Values Grant, the Indiana University Health - Indiana University School of Medicine Strategic Research Initiative, and internal funding from the Department of Medicine, Indiana University School of Medicine, Indianapolis.

\section{Disclosure}

The authors report no conflicts of interest in this work. 


\section{References}

1. Cannon $\mathrm{CP}$, Braunwald $\mathrm{E}, \mathrm{McCabe} \mathrm{CH}$, et al. Intensive versus moderate lipid lowering with statins after acute coronary syndromes. $N$ Engl J Med. 2004;350:1495-1504.

2. Merla R, Reddy NK, Wang F, Uretsky BF, Barbagelata A, Birnbaum Y. Meta-analysis of published reports on the effect statin treatment before percutaneous coronary intervention on periprocedural myonecrosis. Am J Cardiol. 2007;100:770-776.

3. Pasceri V, Patti G, Nusca A, et al; ARMYDA Investigators. Randomized trial of atorvastatin for reduction of myocardial damage during coronary intervention: results from the ARMYDA (atorvastatin for reduction of myocardial damage during angioplasty) study. Circulation. 2004;110:674-678.

4. Briguori C, Visconti G, Focaccio A, et al. Novel approaches for preventing or limiting events (Naples) II trial: impact of a single high loading dose of atorvastatin on periprocedural myocardial infarction. $J$ Am Coll Cardiol. 2009;54(23):2157-2163.

5. Di Sciascio G, Patti G, Pasceri V, Gaspardone A, Colonna G, Montinaro A. Efficacy of atorvastatin reload in patients on chronic statin therapy undergoing percutaneous coronary intervention: results of the ARMYDA-RECAPTURE (atorvastatin for reduction of myocardial damage during angioplasty) randomized trial. J Am Coll Cardiol. 2009;54(6):558-565.

6. Kreutz RP, Flockhart DA. Amlodipine-not a significant contributor to clopidogrel non-response? Heart. 2013;99(7):437-439.

7. Stone GW, Witzenbichler B, Weisz G, et al; ADAPT-DES Investigators. Platelet reactivity and clinical outcomes after coronary artery implantation of drug-eluting stents (ADAPT-DES): a prospective multicentre registry study. Lancet. 2013;382(9892):614-623.

8. Lau WC, Waskell LA, Watkins PB, et al. Atorvastatin reduces the ability of clopidogrel to inhibit platelet aggregation: a new drug-drug interaction. Circulation. 2003;107:32-37.

9. Muller I, Besta F, Schulz C, Zhongyan L, Massberg S, Gawaz M. Effects of statins on platelet inhibition by a high loading dose of clopidogrel. Circulation. 2003;108:2195-2197.

10. Vinholt P, Poulsen TS, Korsholm L, et al. The antiplatelet effect of clopidogrel is not attenuated by statin treatment in stable patients with ischemic heart disease. Thromb Haemost. 2005;94(2):438-443.

11. Saw J, Brennan DM, Steinhubl SR, et al. Lack of evidence of a clopidogrel-statin interaction in the CHARISMA trial. J Am Coll Cardiol. 2007;50:291-295.

12. Kreutz RP, Tantry US, Bliden KP, Gurbel PA. Inflammatory changes during the 'common cold' are associated with platelet activation and increased reactivity of platelets to agonists. Blood Coagul Fibrinolysis. 2007;18:713-718.

13. Kreutz RP, Owens J, Breall JA, et al. C-reactive protein and fibrin clot strength measured by thrombelastography after coronary stenting. Blood Coagul Fibrinolysis. 2013;24(3):321-326.

14. Thygesen K, Alpert JS, White HD, et al; Joint ESC/ACCF/AHA/WHF Task Force for the Redefinition of Myocardial Infarction. Universal definition of myocardial infarction. Circulation. 2007;116(22):2634-2653.

15. Stone NJ, Robinson JG, Lichtenstein AH, et al; American College of Cardiology/American Heart Association Task Force on Practice Guidelines. 2013 ACC/AHA guideline on the treatment of blood cholesterol to reduce atherosclerotic cardiovascular risk in adults: a report of the American College of Cardiology/American Heart Association Task Force on Practice Guidelines. Circulation. 2014;129(25 suppl 2):S1-S45.

Clinical Pharmacology: Advances and Applications

\section{Publish your work in this journal}

Clinical Pharmacology: Advances and Applications is an international, peer-reviewed, open access journal publishing original research, reports, reviews and commentaries on all areas of drug experience in humans. The manuscript management system is completely online and includes a very quick and fair peer-review system, which is all easy to use.
16. Farid NA, Small DS, Payne CD, et al. Effect of atorvastatin on the pharmacokinetics and pharmacodynamics of prasugrel and clopidogrel in healthy subjects. Pharmacotherapy. 2008;28(12):1483-1494.

17. Pelliccia F, Rosano G, Marazzi G, et al. Pharmacodynamic effects of atorvastatin versus rosuvastatin in coronary artery disease patients with normal platelet reactivity while on dual antiplatelet therapy - the PEARL randomized cross-over study. Eur J Pharmacol. 2014;725:18-22.

18. Park Y, Jeong YH, Tantry US, et al. Accelerated platelet inhibition by switching from atorvastatin to a non-CYP3A4-metabolized statin in patients with high platelet reactivity (ACCEL-STATIN) study. Eur Heart J. 2012;33(17):2151-2162.

19. Kim GB, Kim JK, Park S, et al. Effect of atorvastatin and clopidogrel co-administration after coronary stenting in Korean patients with stable angina. Korean Circ J. 2011;41(1):28-33.

20. Mitsios JV, Papathanasiou AI, Rodis FI, Elisaf M, Goudevenos JA, Tselepis AD. Atorvastatin does not affect the antiplatelet potency of clopidogrel when it is administered concomitantly for 5 weeks in patients with acute coronary syndromes. Circulation. 2004;109:1335-1338.

21. Wenaweser P, Windecker S, Billinger M, et al. Effect of atorvastatin and pravastatin on platelet inhibition by aspirin and clopidogrel treatment in patients with coronary stent thrombosis. Am J Cardiol. 2007;99:353-356.

22. Gorchakova O, von Beckerath N, Gawaz M, et al. Antiplatelet effects of a $600 \mathrm{mg}$ loading dose of clopidogrel are not attenuated in patients receiving atorvastatin or simvastatin for at least 4 weeks prior to coronary artery stenting. Eur Heart J. 2004;25:1898-1902.

23. Stern RH, Gibson DM, Whitfield LR. Cimetidine does not alter atorvastatin pharmacokinetics or LDL-cholesterol reduction. Eur J Clin Pharmacol. 1998;53(6):475-478.

24. Leoncini M, Toso A, Maioli M, et al. High-dose atorvastatin on the pharmacodynamic effects of double-dose clopidogrel in patients undergoing percutaneous coronary interventions: the ACHIDO (atorvastatin and clopidogrel high dose in stable patients with residual high platelet activity) study. JACC Cardiovasc Interv. 2013;6(2):169-179.

25. Tekten T, Ceyhan C, Ercan E, Onbasili AO, Turkoglu C. The effect of atorvastatin on platelet function in patients with coronary artery disease. Acta Cardiol. 2004;59(3):311-315.

26. Tirnaksiz E, Pamukcu B, Oflaz H, Nisanci Y. Effect of high dose statin therapy on platelet function; statins reduce aspirin-resistant platelet aggregation in patients with coronary heart disease. J Thromb Thrombolysis. 2009;27(1):24-28.

27. Pelliccia F, Rosano G, Marazzi G, et al. Pharmacodynamic comparison of pitavastatin versus atorvastatin on platelet reactivity in patients with coronary artery disease treated with dual antiplatelet therapy. Circ J. 2014;78(3):679-684.

28. Ojeifo O, Wiviott SD, Antman EM, et al. Concomitant administration of clopidogrel with statins or calcium-channel blockers: insights from the TRITON-TIMI 38 (trial to assess improvement in therapeutic outcomes by optimizing platelet inhibition with prasugrel-thrombolysis in myocardial infarction 38). JACC Cardiovasc Interv. 2013;6(12):1275-1281.

29. Saw J, Steinhubl SR, Berger PB, et al; CREDO Investigators. Lack of adverse clopidogrel-atorvastatin clinical interaction from secondary analysis of a randomized, placebo-controlled clopidogrel trial. Circulation. 2003;108:921-924.

Visit http://www.dovepress.com/testimonials.php to read real quotes from published authors. 